the longest duration of respiratory support. Nasal injury is usually mild and resolves with cessation of NCPAP. It can however lead to permanent disfigurement with long term functional sequelae. High flow nasal cannulae (HFNC) offer an alternative modality of respiratory support and may allow for decreased infant handling and less nasal trauma than NCPAP.

Methods 132 ventilated infants $<32$ weeks of gestation were randomised to receive either HFNC $(\mathrm{N}=67)$ or NCPAP $(\mathrm{N}=65)$ following primary extubation. A nasal trauma score was adapted from Kaufman [EPAS 2007:61390] and validated. Nasal trauma scores were recorded for 7 days post-extubation (Figure 1). Each episode of prong repositioning was recorded for 72 hours post-extubation. Results

Abstract 397 Table 1

\begin{tabular}{lll}
\hline & HFNC $\mathbf{N}=\mathbf{6 7}$ & NCPAP N=65 \\
\hline Mean Nasal Trauma Score (SD) & $3.12(7.16)$ & $11.81(10.71)^{*} \mathrm{p}<0.001$ \\
Mean Prong repostions (SD) & $8.25(3.25)$ & $16.69(6.29){ }^{*} \mathrm{p}<0.001$ \\
\hline
\end{tabular}

Conclusions HFNC results in significantly less nasal trauma and fewer prong repositions than NCPAP. These are important benefits that should be considered especially if HFNC and NCPAP are demonstrated to be equally efficacious for post-extubation respiratory support in preterm infants.

\section{SEVEN VENTILATORS DELIVERING NASAL CPAP CHALLENGED WITH LEAKAGE: AN EXPERIMENTAL PILOT STUDY}

doi:10.1136/archdischild-2012-302724.0398

${ }^{1} \mathrm{~T}$ Drevhammar, ${ }^{2} \mathrm{~K}$ Nilsson, 'B Jonsson. 'Department of Woman and Child Health, Karolinska Institutet and University Hospital, Stockholm; '2Ventinvent AB, Östersund, Sweden

Introduction Nasal Continuous Positive Airway Pressure (nCPAP) is an established treatment for respiratory distress in neonates. Most modern ventilators are able to provide nCPAP. Compared to traditional nCPAP delivery systems ventilators are more complex and allow correction for leakage. There have been no large studies examining the response to leakage for nCPAP delivered by ventilators. The aim of this pilot study was to compare pressure stability for nCPAP delivered by ventilators using simulated neonatal breathing and constant leakage.

Methods Neonatal breathing was simulated by using a mechanical lung simulator. Seven ventilators were tested with recommended prongs, humidifier and tubing. Tests were performed with a breath profile from a $3.4 \mathrm{~kg}$ infant and nCPAP of $4 \mathrm{~cm} \mathrm{H}_{2} \mathrm{O}$. Constant leakage at 1-2-3-4 1/min was introduced after 30 breaths. Pressure stability was measured as pressure increase and decrease from mean pressure. Leakage stability was measured as change in mean pressure. Calculations were performed for each breath.

Results The pressure stability of the tested ventilators showed large variations before introducing leakage. Fabian, Evita XL and SERVO-i were the most pressure stable systems (with and without leakage). Changes in mean pressure with leakage also showed large variations. Four of the ventilators had leakage compensation.

Conclusion The tested ventilators showed large variations in pressure stability and ability to maintain pressure when exposed to leakage. Ability to maintain mean pressure and provide pressure stable nCPAP are different aspects of nCPAP systems. Being able to compensate for leakage does not necessarily give more pressure stable nCPAP.

\section{AUTOMATIC CONTROL OF THE INSPIRED OXYGEN FRACTION IN PRETERM INFANTS. PRELIMINARY RESULTS OF A MULTICENTER RANDOMIZED CROSS-OVER TRIAL}

doi:10.1136/archdischild-2012-302724.0399
'A Hallenberger, 'MS Urschitz, "I Müller-Hansen, ${ }^{2} \mathrm{~S}$ Miksch, ${ }^{2} \mathrm{~A}$ Seyfang, ${ }^{3} \mathrm{~W}$ Horn ${ }^{1}$ CF Poets. 'Department of Neonatology, University Hospital Tuebingen, Tuebingen, Germany; ${ }^{2}$ Institute of Software Technology and Interactive Systems (ISIS), Vienna University of Technology: ${ }^{3}$ Section for Artificial Intelligence, Center for Med. Statistics, Informatics and Intelligent Systems, Medical University of Vienna, Vienna, Austria

Background and Aims In preterm infants receiving supplemental oxygen, manual control of the inspired oxygen fraction is often time-consuming and inappropriate. We developed a system for automatic oxygen control $\left(\mathrm{FiO}_{2}\right.$-Controller) and hypothesized that this system is more effective than routine manual oxygen control in maintaining target arterial oxygen saturation levels.

Methods We performed a multicenter randomized controlled cross-over clinical trial in preterm infants receiving mechanical ventilation or nasal continuous positive airway pressure and supplemental oxygen. Periods with routine manual oxygen control (period 1) were compared to periods of routine manual oxygen control supported by the $\mathrm{FiO}_{2}$-Controller (period 2).

Results Preliminary results including 18 patients are presented. The median (range) percentage of time with arterial oxygen saturation levels within target range (90-95\%) was 59.3\% (37.9-99.5) for period 1, and 69.4\% (43.8-95.4) for period 2. Final analysis including significance testing is pending.

Conclusions Automatic oxygen control may improve oxygen administration to preterm infants receiving mechanical ventilation or nasal continuous positive airway pressure.

\section{OSCILLATION TRANSMISSION AND VENTILATION DURING FACE MASK-DELIVERED HIGH FREQUENCY OSCILLATORY VENTILATION IN INFANTS: A BENCH STUDY WITH ACTIVE LUNG SIMULATOR}

doi:10.1136/archdischild-2012-302724.0400

'D De Luca, ${ }^{2} \mathrm{R}$ Costa, ${ }^{2} \mathrm{G}$ Spinazzola, ${ }^{2} \mathrm{~F}$ Cipriani, ${ }^{1} \mathrm{M}$ Piastra, ${ }^{1,2} \mathrm{G}$ Conti. ${ }^{1} P I C U ;{ }^{2}$ Ventilab, University Hospital A.Gemelli, Catholic University of the Sacred Heart, Roma, Italy

Background Noninvasive high frequency oscillatory ventilation (nHFOV) has been applied through nasal prongs as a new respiratory technique in preterm neonates and has been found to reduce $\mathrm{CO}_{2}$, but it has never been studied in bigger infants. Its mechanical properties when applied through a face mask are not known.

Methods We modeled the application of face mask-NHFOV in infants using a pediatric mannequin connected to an active lung simulator (ASL5000). This was set mimicking the mechanical properties of a normal lung (Crs $1 \mathrm{~mL} / \mathrm{cmH}_{2} \mathrm{O} / \mathrm{Kg}$; Raw: $40 \mathrm{cmH}_{2} \mathrm{O} / \mathrm{L} /$ sec; Pmus $6 \mathrm{cmH}_{2} \mathrm{O}$; rate: 40 breaths/min) in a male infant at 1 year, $8 \mathrm{Kg}, 3^{\text {rd }}$ percentile for age. NHFOV parameters were sequentially changed. Spontaneous tidal volume (sTv), oscillatory stroke volume (oTv) and oscillation amplitude (DeltaPdist) at the lung simulator were recorded. Oscillatory pressure ratio (OPR: DeltaPdist/DeltaP) and the theoretical ventilation during HFOV (DCO2=frequency $\mathrm{x}$ oTv ${ }^{2}$ ) were also calculated.

Results Mean oTv, OPR and DCO2 were $1.9 \pm 0.7 \mathrm{~mL} / \mathrm{Kg}, 0.05 \pm 0.02$ and $221 \pm 136 \mathrm{~Hz} \times \mathrm{mL}^{2} / \mathrm{Kg}$, respectively. Significant correlations were found between OPR and oTv $(r=0.48 ; p<0.001)$ and OPR and DCO2 ( $r=0.47 ; p<0.001) . \mathrm{oTv}$ significantly correlates with sTv $(\mathrm{r}=0,885 ; \mathrm{p}<0,001)$. At a multivariate regression OPR was the factor more strongly associated with oTv (st. $\beta=0.88$ ) and DCO2 (st. $\beta=0.96 ; p<0.001$ ).

Discussion NHFOV through face mask is feasible. Oscillation amplitude is dampened by the interface and may reach in the lung $11 \%$ of the set value. Nonetheless, in this model adequate Tv and DCO2 are reached and OPR was the factor more strongly influencing ventilation. 
401 VENTILATION PARAMETERS DURING RESUSCITATION: COMPARISON OF TWO DIFFERENT DEVICES IN A MANNEQUIN MODEL WITH AND WITHOUT DISTRACTION

doi:10.1136/archdischild-2012-302724.0401

1,2N Gupta, 'M Thio, ${ }^{1,3} \mathrm{JA}$ Dawson, 'COF Kamlin, 'GM Schmoelzer, ${ }^{1,3} \mathrm{PG}$ Davis. 'Newborn Services, The Royal Women's Hospital, Melbourne, VIC, Australia; ${ }^{2}$ Neonatal Unit, John Radcliffe Hospital, Oxford, UK; ' ${ }^{3}$ urdoch Children's Research Institute, Melbourne, VIC, Australia

Background and Aims Positive pressure ventilation is a common intervention in neonatal resuscitation. Distraction, type of device and experience may influence performance. Studies have not included self-inflating bags (SIB) equipped with a PIP manometer and expiratory PEEP valve. We aimed to compare clinicians' ability to ventilate a mannequin using a SIB with additional manometers against a T-piece (TP), with and without distraction

Method 50 medical and nursing staff were tested using standarised case scenarios with a leak free intubated mannequin. Participants targeted PIP $30 \mathrm{cmH}_{2} \mathrm{O}$, PEEP $5 \mathrm{cmH}_{2} \mathrm{O}$, inflation rate (IR) 60 inflations/minute with both devices in randomised order. We analysed PIP, PEEP, IR, expired tidal volume (TVe), professional group and compared devices during baseline and 3 minutes of distraction.

Results 12,981 inflations were analysed. Mean (SD) ventilation parameters are shown in table.

\section{Abstract 401 Table 1}

\begin{tabular}{lcccc}
\hline Parameter & \multicolumn{2}{c}{ Baseline } & \multicolumn{2}{c}{ Distraction } \\
\hline & TP & SIB & TP & SIB \\
PIP & $29.3(0.6)$ & $29.0(2.3)$ & $29.3(0.7)$ & $28.9(3.5)$ \\
PEEP & $4.2(0.6)$ & $5.5(0.9)$ & $4.2(0.6)$ & $5.5(0.9)$ \\
IR & $53.6(10.3)$ & $56.6(11.7)$ & $53(13)$ & $56.2(13.5)$ \\
TVe & $10.2(1.8)$ & $9.7(0.9)$ & $10.3(1.9)$ & $9.6(1.5)$ \\
\hline
\end{tabular}

When analysed by operator, more variation was observed in IR $(\mathrm{P}=0.029)$ and TVe $(\mathrm{P}=0.002)$ with $\mathrm{SIB}$ during distraction.

Conclusions Clinicians' general performance when using a SIB where PIP and PEEP are displayed is comparable to a T-Piece, however more variation in IR and TVe occurs under distraction. This may be relevant in a real resuscitation.

\section{EFFECT OF ANTENATAL CORTICOSTEROIDS IN ACTIVITY AND EXPRESSION OF SECRETORY PHOSPHOLIPASE A2 AND TNF ALFA IN LUNG OF NEWBORN RATS}

doi:10.1136/archdischild-2012-302724.0402

${ }^{1}$ A Remesal, 'L San Feliciano, ${ }^{2} \mathrm{D}$ de Luca, ${ }^{3} \mathrm{D}$ Benito, ${ }^{2} \mathrm{~A}$ Minucci, ${ }^{4} \mathrm{M}$ Isidoro-García, ${ }^{5} \mathrm{D}$ Ludeña. 'Pediatrics, Salamanca University Hospital, University of Salamanca, Salamanca, Spain; 'Laboratory Medicine, University Hospital A. Gemelli, Catholic

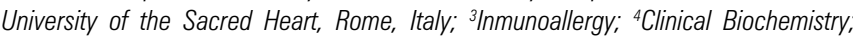
${ }^{5}$ Cellular Biology and Pathology, Salamanca University Hospital, University of Salamanca, Salamanca, Spain

Introduction The sPLA2 plays an important role in the development of acute respiratory distress syndrome. It is regulated by many factors including steroids and TNFa. Antenatal corticosteroids are recommended for preventing respiratory distress syndrome in preterm infants. Recent studies suggest that betamethasone might be a better choice than dexamethasone. The aim of this study is evaluate differences between both antenatal corticosteroids in the regulation of sPLA2 and TNFa.

Methods Dexamethasone, betamethasone or saline were administered intravenously to pregnant Wistar rats on the $20^{\text {th }}$ and $21^{\text {st }}$ days of gestation. We evaluated pulmonary sPLA2 and TNFa mRNA in newborn rats at birth by RT-PCR. We also evaluated sPLA2 activity by an ultrasensitive non-radioactive method on microplate and the TNFa protein expression by ELISA. Differences between the groups were determined by one way ANOVA ( $p<0.05)$.

Results We observed a statistically significant decrease in the sPLA2 mRNA in the betamethasone (0.61) and dexamethasone (0.26) groups respect the control (1.05) group and a decrease in the sPLA2 activity in the betamethasone group (33.78) respect the control group (50.74). We observed a statistically significant decrease in the TNFa protein in the betamethasone group (472.61) respect the dexamethasone group (768.65)

Conclusions Antenatal glucocorticoids inhibits the expression of sPLA2 through the reduction of TNFa in the lung of newborn rats. These potential beneficial effects are more evident in the group treated with antenatal betamethasone. Our studies also support the notion that betamethasone could be the drug of choice for treating pregnant women at risk of preterm delivery.

\section{SURFACTANT DISATURATED-PHOSPHATIDYLCHOLINE KINETICS IN PNEUMONIA BY STABLE ISOTOPES}

doi:10.1136/archdischild-2012-302724.0403

${ }^{1} \mathrm{M}$ Facco Marcazzò, 'M Simonato, II Ferrino, ' $\mathrm{G}$ Verlato, ${ }^{2} \mathrm{M}$ Nespeca, ${ }^{2} \mathrm{G}$ Ciambra ${ }^{2} \mathrm{C}$ Giorgetti, ${ }^{3 P E}$ Cogo, ${ }^{2} \mathrm{VP}$ Carnielli. 'Department of Women's and Children's Health, University of Padova, Padova, ${ }^{2}$ Neonatal Medicine Salesi Children's Hospital, Polytechnic University of Marche and University of Ancona, Ancona; ${ }^{3}$ Medical Cardiac and Cardiac Surgical Pediatrics, Bambino Gesù Children's Hospital, Roma, Italy

Background and Aim Whether pulmonary surfactant deficiency or dysfunction contributes to the pathogenesis of neonatal pneumonia is still debated. Aim of our study was to measure surfactant disaturated-phosphatidylcholine (DSPC) kinetics and surfactant specific proteins A and B (SP-A, SP-B) amount in term newborns with pneumonia using stable isotopes as tracers.

Methods Twenty-seven term newborns (GA 39.0土1.5 weeks, BW $3165 \pm 602 \mathrm{~g}$ ) requiring mechanical ventilation were studied. Twelve had severe pneumonia and 15 no lung disease. All newborns received intra-tracheally $2 \mathrm{mg} / \mathrm{kg} \mathrm{U}{ }^{13} \mathrm{C}$-DPPC mixed with $2 \mathrm{mg} / \mathrm{kg}$ of exogenous surfactant. Isotopic enrichment of DSPC palmitate was measured from tracheal aspirates by mass spectrometry and kinetic data calculated. Surfactant proteins were measured by ELISA. Data were expressed as median (interquartile range) and comparisons were performed by Mann-Whitney test. $\mathrm{p}<0.05$ was regarded as statistically significant.

Results DSPC pool size (PS) was $9.3 \mathrm{mg} / \mathrm{kg}(3.1-30.2)$ in newborns with pneumonia and $38.0 \mathrm{mg} / \mathrm{kg}$ (24.9-124.6) in controls, $\mathrm{p}=0.016$. DSPC half-life (HL) was $12.7 \mathrm{~h}(5.2-20.2)$ and $25.6 \mathrm{~h}(18.5-65.6)$ in newborns with pneumonia and in controls, respectively $(p=0.004)$. Analysis for SP-A and SP-B are in progress. In newborns with pneumonia a correlation was found between DSPC kinetic parameters and oxygen requirement (DSPC PS and mean $\mathrm{FiO} 2, \mathrm{R}=-0.61$, $\mathrm{p}=0.047$; DSPC HL and mean FiO2, $\mathrm{R}=-0.54$, $\mathrm{p}=0.086$ ).

Conclusions Surfactant DSPC kinetics was found to be markedly impaired in term newborns with pneumonia. Preliminary data suggest that these alterations correlate with disease severity; thus, studies on exogenous surfactant therapy and on the effect on surfactant metabolism are needed.

\section{4 \\ DSPC-PALMITATE KINETIC IN A MODEL OF LUNG UNILATERAL ACID INJURY}

doi:10.1136/archdischild-2012-302724.0404

${ }^{1} \mathrm{G}$ Lamonica, ${ }^{2} \mathrm{~L}$ Vedovelli, ${ }^{3} \mathrm{M}$ Amigoni, ${ }^{3} \mathrm{~V}$ Zambelli, ${ }^{3} \mathrm{M}$ Scanziani, ${ }^{1} \mathrm{M}$ Facco Marcazzò, ${ }^{3} \mathrm{G}$ Bellani, ${ }^{4} \mathrm{PE}$ Cogo. 'Department of Pediatrics; ' $D$ epartment of Pharmacology and Anesthesiology, University of Padua, Padova; ${ }^{3}$ Experimental Medicine, University Milano-Bicocca, Monza; 'Medical Cardiac and Cardiac Surgical Pediatrics, Bambino Gesù Children's Hospital, IRCCS, Roma, Italy 